\title{
УНИФИКАЦИЯ ОПЛАТЫ ТРУДА ПЕДАГОГОВ
}

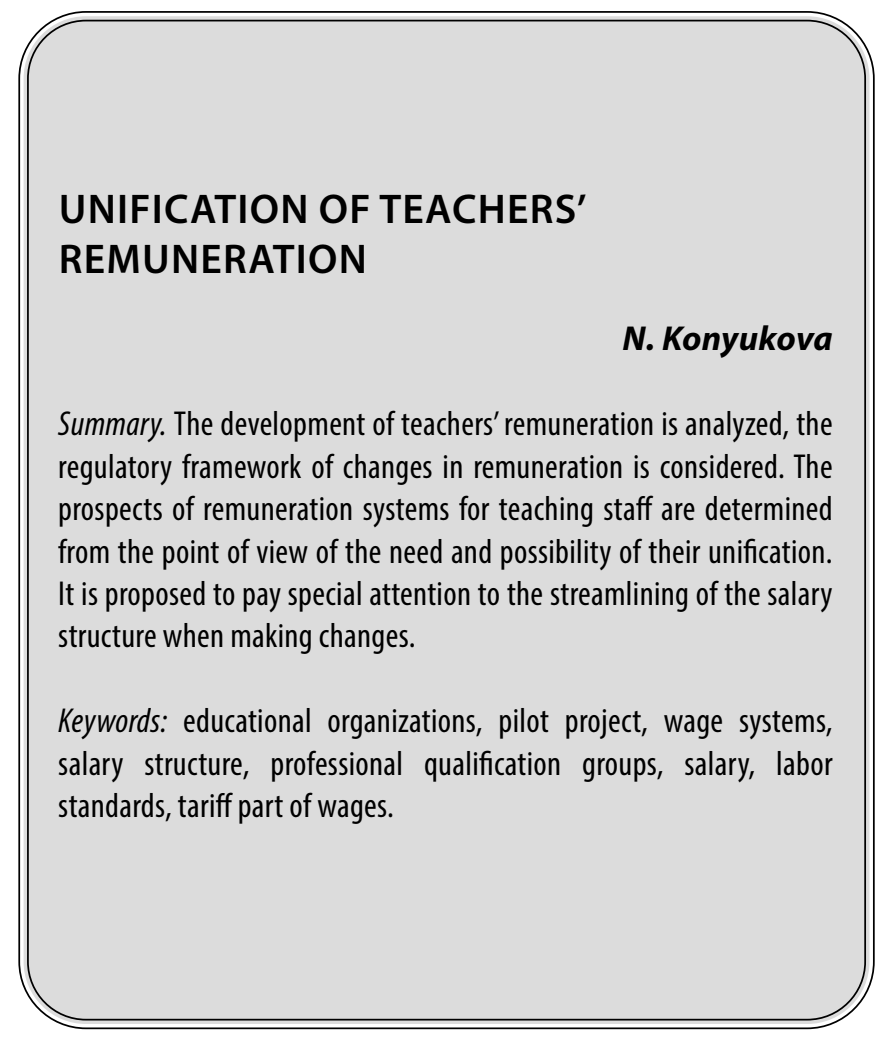

O бразование и его развитие затрагивает интересы и благополучие каждого отдельного человека, создает фундамент будущего страны. Именно поэтому государство уделяет особое внимание развитию образовательных организаций. На это направлены Национальные проекты и выделяемые финансовые ресурсы. Оплата труда работников образовательных организаций находится в центре внимания на всех уровнях управления государством.

Цель работы - на основе анализа развития оплаты труда педагогических работников общего образования рассмотреть перспективы и возникающие проблемы унификации оплаты труда педагогов. Задачами работы является рассмотрение нормативно-правовой базы, вносящей изменения в оплату труда работников образования, анализ существующих систем оплаты труда, а также определение дальнейшего развития систем оплаты труда педагогических работников с точки зрения необходимости и возможности их унификации.

Информационную базу, проведенного исследования, составили материалы, собранные в процессе участия в программе «Подготовка управленческих кадров в сфере здравоохранения, образования и культуры»,

\author{
Конюкова Наталья Ивановна \\ К.э.н., доцент, Сибирский институт управления - \\ филиал РАНХИГС, РФ, г. Новосибирск
}

Аннотация. Анализируется развитие оплаты труда педагогов, рассматривается нормативно-правовая база изменений в оплате труда. Определяются перспективы систем оплаты труда педагогических работников с точки зрения необходимости и возможности их унификации. Предлагается при проведении изменений особое внимание уделить упорядочению структуры заработной платы.

Ключевые слова: общеобразовательные организации, пилотный проект, системы оплаты труда, структура заработной платы, профессиональные квалификационные группы, оклад, нормы труда, тарифная часть оплаты труда.

где рассматривалось, в том числе, развитие оплаты труда педагогов и необходимость ее унификации.

Основные проблемы в оплате труда педагогов возникли при переходе на новую систему оплаты труда. Бюджетные учреждения при установлении порядка определения тарифной части заработной платы могли использовать одну из трех методик. Это модельная методика, схема окладов по профессиональным группам или «базовая единица и повышающие коэффициенты». Первая методика была предложена Министерством образования РФ, вторая и третья Министерством труда РФ. При этом принципы определения тарифной части заработной платы, предложенные в методиках принципиально отличались.

При применении модельной методики вводилось понятие «стоимость одного ученико-часа». Стоимость ученико-часа рассчитывалась делением годового фонда оплаты труда на годовую норму нагрузки. Заработная плата педагога ставилась в прямую зависимость от количества учеников в классе.

При применении второй методики, а именно, оплате по профессионально квалификационным группам 
(ПКГ), заработная плата педагога зависела от установленного уровня ПКГ и нормы часов педагогической нагрузки.

Третья методика, «базовая единица и повышающие коэффициенты» ставила заработную плату педагога в зависимость от типа образовательного учреждения, поскольку по ним шла дифференциация базовых должностных окладов и повышающих коэффициентов к окладам за квалификацию и результаты работы.

Это означало, что при модельной методике применялась сдельная форма оплаты труда, а при «базовой единице» и ПКГ повременная форма оплаты труда.

Фактически оплата труда педагогов отличалась не только в абсолютном выражении, но и по принципу начисления тарифной заработной платы. Это не давало возможности осуществлять общее управление оплатой труда в общеобразовательных организациях и вызывало серьезные проблемы и недовольства.

Дальнейшее совершенствование, установление и изменение систем оплаты труда в общем образовании осуществлялось с учетом принятой программы поэтапного совершенствования системы оплаты труда в государственных (муниципальных) учреждениях на 2012-2018 годы. Программа содержала анализ текущей ситуации по формированию системы оплаты труда работников государственных (муниципальных) учреждений, цели и задачи совершенствования системы оплаты труда, мероприятия, этапы и ресурсное обеспечение реализации программы, а также ожидаемые результаты.

Программой был предусмотрен комплекс мероприятий, направленных на сохранение кадрового потенциала, повышение престижности и привлекательности работы в учреждениях, обеспечение соответствия оплаты труда работников качеству оказания ими государственных (муниципальных) услуг.

Достижение целей программы требовало совершенствования системы оплаты труда работников учреждений, ориентированной на достижение конкретных показателей качества и количества оказываемых государственных (муниципальных) услуг, создание прозрачного механизма оплаты труда руководителей учреждений, развитие кадрового потенциала работников учреждений, а также создание организационных и правовых условий для достижения целевых показателей уровня средней заработной платы отдельных категорий работников.

Системы оплаты труда работников учреждений должны обеспечивать дифференциацию оплаты труда работников, выполняющих работы различной сложности, а также установление оплаты труда в зависимости от качества оказываемых государственных (муниципальных) услуг и эффективности деятельности работников по заданным критериям и показателям.

Предусматривалось утверждение Правительством Российской Федерации государственных программ и планов мероприятий («дорожных карт») по развитию отраслей социальной сферы, содержащих целевые показатели (индикаторы) развития отраслей и меры, обеспечивающие их достижение. В «дорожные карты» включались, в том числе, мероприятия по совершенствованию систем оплаты труда работников в соответствующих сферах, обеспечивающие за счет доходов от всех направлений деятельности учреждения повышение оплаты труда работников. Повышение оплаты труда работников также должно было быть обусловлено достижением конкретных показателей качества и количества оказываемых государственных (муниципальных) услуг, а также мероприятиями по проведению структурных реформ в соответствующих отраслях, обеспечивающих возможности использования не менее трети необходимых ресурсов для повышения оплаты труда за счет реорганизации неэффективных организаций и программ.

При определении потребности в бюджетных ассигнованиях за счет бюджетов всех уровней на увеличение нормативных затрат на оказание государственных (муниципальных) услуг в целях совершенствования системы оплаты труда работников образования учитывалась нормативная численность работников для оказания этих услуг.

При оценке соотношения заработной платы отдельных категорий работников и средней заработной платы в регионе учитывалась вся заработная плата, полученная работником за счет всех источников. При выделении дополнительного финансирования за счет средств соответствующих бюджетов принималось во внимание выполнение целевых индикаторов развития отраслей, установленных в «дорожных картах», объем привлеченных средств за счет реорганизации неэффективных учреждений, иных источников и других мероприятий по оптимизации расходов, а также данные статистического наблюдения показателей заработной платы работников образования.

Достижение показателей по заработной плате, осуществлялось в отношении соответствующей категории работников в целом. При этом сохранялось обусловленная различиями в сложности труда дифференциация в оплате труда работников, занимающих различные должности, относящиеся к одной категории. 
Принятие и реализация положений программы поэтапного совершенствования оплаты труда существенным образом способствовало модернизации оплаты труда в общем образовании, но не решило проблемы единообразия систем оплаты труда, поскольку начисление тарифной части заработной платы, по-прежнему, осуществлялось с применением в регионах разных методик.

Принимаемые в дальнейшем нормативные документы были призваны устранить эту проблему. Прежде всего это Методические рекомендации по формированию систем оплаты труда работников общеобразовательных организаций[3] и Единые рекомендации по установлению на федеральном, региональном и местном уровнях систем оплаты труда работников государственных и муниципальных учреждений на 2021 год [2].

Методические рекомендации предусматривают, что при разработке нормативных документов по оплате труда, органы государственной власти субъектов Российской Федерации, органы местного самоуправления должны устанавливать оклады работников общего образования по профессионально-квалификационным группам должностей работников образования.

Единые рекомендации содержат указание на необходимость применять системы оплаты труда работников общеобразовательных организаций с учетом методических рекомендаций по формированию системы оплаты труда работников общеобразовательных организаций. Органам государственной власти субъектов Российской Федерации и органам местного самоуправления рекомендуется устанавливать минимальные оклады по квалификационным уровням профессиональных квалификационных групп.

Методические рекомендации и Единые рекомендации имеют целью упорядочивание принципов начисления заработной платы работников общеобразовательных организаций.

Доведение уровня заработной платы отдельных категорий работников социальной сферы до целевых индикаторов соответствующей отрасли не полностью решает вопросы эффективности систем оплаты труда. Важным, с точки зрения результативности работы учреждения и удовлетворенности сотрудников, является структура заработной платы, складывающаяся в учреждении, и обоснованность начисления стимулирующих выплат.

Установление систем оплаты труда в любом учреждении предполагает определение тарифной части заработной платы (оклада, тарифной ставки) за норму труда, определение результата деятельности сотрудников, подразделений для начисления стимулирующих выплат, определение соотношения между тарифной и стимулирующей частью заработной платы.

Методическими рекомендациями предусмотрено, что удельный вес оклада в структуре заработной платы должен составлять не менее 70 процентов. Вместе с тем наши исследования показали, что тарифная часть (выплаты по окладам) в структуре заработной платы по рассмотренным общеобразовательным организациям составляет примерно 30 процентов. Имеются существенные различия окладов между регионами, при этом тариф за норму педагогической нагрузки остается крайне низким.

Обусловлено это тем, что выделяемые общеобразовательным организациям средства на повышение заработной платы направляются не на увеличение тарифной части заработной платы, а на увеличение стимулирующих выплат.

Одна из возможных причин обусловлена финансовыми аспектами. Дело в том, что тарифная часть заработной платы является гарантированной и не может быть уменьшена даже при неблагоприятной финансовой ситуации. Стимулирующая часть заработной платы, гарантированной не является, она связана с достигаемым организацией и отдельными работниками результатом, и при отсутствии результата, может быть уменьшена или же может вовсе не выплачиваться. Регионы, направляя средства на повышение заработной платы в стимулирующий фонд, пытаются снизить риск неполучения средств на повышение заработной платы из федерального бюджета.

Финансирование повышения заработной платы в общеобразовательных организациях осуществляется в основном за счет средств региональных бюджетов, которые получают на эти цели субвенции и дотации из федерального бюджета. Постановлением Правительства РФ № 416 от 2 апреля 2020 года утверждена методика, в соответствии с которой определено, что дотации бюджетам субъектов Российской Федерации предоставляются в 2020 году для компенсации дополнительных расходов консолидированных бюджетов субъектов Российской Федерации на сохранение целевых показателей повышения оплаты труда работников бюджетной сферы. Обращает на себя внимание временной характер действия методики. Гарантированность тарифной части заработной платы и отсутствие долгосрочных финансовых гарантий обеспечения повышения заработной платы работников общеобразовательных организаций является, на наш взгляд, основной причиной сохранения в структуре 
заработной платы крайне низкого удельного веса тарифной части.

По регионам, не смотря на принимаемые федеральными властями усилия, наблюдается искаженная структура заработной платы и отсутствует четкий порядок определения тарифа за норму труда, что вызывает недовольство работников и в значительной степени обусловило необходимость унификации оплаты труда в педагогов.

Своевременным и обоснованным, в связи с этим, является принятие поправок в Трудовой кодекс РФ [1]. Суть поправок состоит в том, что Правительство Российской Федерации получает право непосредственно устанавливать порядок оплаты труда работников учреждений, оказывающих государственные (муниципальные) услуги. Это коснется установления тарифной части заработной платы (окладов, тарифных ставок), выплат компенсационного характера, стимулирующих выплат. Принятые изменения позволят обеспечить единый порядок в построении систем оплаты труда в регионах.

Кроме того, в 2021-2023 годах в Белгородской, Нижегородской, Сахалинской, Ярославской областях и Республике Мордовия, предполагается реализация пилотного проекта в целях утверждения требований к системе оплаты труда педагогических работников государственных и муниципальных учреждений системы образования. Проектом предусмотрено, что системы оплаты труда педагогических работников образовательных организаций - участников пилотного проекта включают установленные органом государственной власти субъекта Российской Федерации: ставки заработной платы (должностные оклады) педагогических работников на основе квалификационного уровня профессиональной квалификационной группы должностей педагогических работников, выплаты компенсационного и стимулирующего характера [4].

Обращает на себя внимание то, что порядок установления ставок заработной платы (должностные оклады) и определения их размеров утверждается Правительством Российской Федерации. Стимулирующие и компенсационные выплаты устанавливаются в соответствии с утверждаемым Правительством Российской Федерации перечнем выплат, размерами и условиями их назначения. Фактически это означает централизацию и унификацию оплаты труда педагогов.

Законодательством субъекта Российской Федерации могут устанавливаться иные выплаты компенсационного и стимулирующего характера, их размеры и условия назначения. Тарифная часть заработной пла- ты педагогов в рамках реализации пилотного проекта не может быть ниже ее размера, при условии сохранения объема учебной работы.

Развитие оплаты труда педагогов должно идти по пути совершенствования структуры заработной платы и нормирования труда. Это касается определения тарифа заработной платы за норму труда, а также соотношении между базовой частью заработной платы и стимулирующими выплатами.

Возможным решением данной проблемы является предоставление регионам долгосрочных финансовых гарантий по обеспечению повышения заработной платы работников общеобразовательных организаций при условии сохранения заработной платы педагогических работников на уровне средней заработной платы по экономике соответствующего региона и доведения удельного веса тарифа в структуре заработной платы до 70 процентов. Долгосрочные финансовые гарантии позволят изменить структуру заработной платы, увеличить оплату труда за установленную норму часов педагогической нагрузки.

Важно использовать возможности тарифных соглашений. Необходимо во все отраслевые соглашения, заключаемые на региональном уровне внести пункт о доведении базовой части в структуре заработной платы до 70\%. Сделать обязательным включение в коллективный договор общеобразовательной организации данного пункта. Средства, на повышение заработной платы педагогических работников направлять на увеличение её тарифной части. Имеющиеся средства перераспределить между тарифной частью и стимулирующими выплатами в сторону увеличения в структуре заработной платы тарифной части и доведении её уровня до 70\%.

Изменение структуры заработной платы позволит, не увеличивая абсолютный уровень заработной платы, а лишь изменив её структуру, повысить гарантированность оплаты труда за установленную норму часов педагогической нагрузки.

Важным является определять долю фонда оплаты труда на оплату труда работников административно-управленческого и вспомогательного персонала. Эта доля в фонде оплаты труда учреждения должна быть не более 40 процентов. Совершенствование структуры кадров приведет к перераспределению фонда оплаты труда, что послужит дополнительным источником увеличения заработной платы педагогических работников образовательных организаций.

Унификация систем оплаты труда педагогических работников государственных и муниципальных учреж- 
дений системы образования позволит сделать систему оплаты труда этой категории работников более понятной, прозрачной и справедливой. Повышение удовлетворенности учителя получаемым вознаграждением позволит достичь целей развития системы общего образования, а именно, обеспечить качественную работу учителя и качественные условия обучения и, как следствие, качественное образование.

\section{ЛИТЕРАТУРА}

1. Федеральный закон от 9 ноября 2020 г. N362-Ф3 «0 внесении изменений в Трудовой кодекс Российской Федерации». URL: http://publication.pravo.gov. ru/Document/View/0001202011090012?index=0\&rangeSize=1 [дата обращения 02.10.2021]

2. Единые рекомендации по установлению на федеральном, региональном и местном уровнях систем оплаты труда работников государственных и муниципальных учреждений на 2021 год. URL: http://www.consultant.ru/document/cons_doc_LAW_372123/ [дата 0бращения 02.10.2021]

3. Методические рекомендации по формированию систем оплаты труда работников общеобразовательных организаций от 29.12.2017 N BП-1992/02. URL: http://docs.cntd.ru/document/556329656 [дата обращения 02.10.2021]

4. Проект постановления Правительства Российской Федерации «0 реализации пилотного проекта в целях утверждения требований к системе оплаты труда педагогических работников государственных и муниципальных учреждений системы образования» URL: https://regulation.gov.ru/ projects\#npa=119980 [дата обращения 02.10.2021]

5. Лежнева Л. Не окладом единым: в России захотели выровнять зарплаты учителей (Сенаторы предлагают правительству изучить проблему перекосов в окладах педагогов) // Известия, 6 декабря 2019. - [Электронный ресурс]. URL: https://iz.ru/950183/liubov-lezhneva/ne-okladom-edinym-v-rossiizakhoteli-vyravniat-zarplaty-uchitelei

6. Соловьева К. Почему регионы отказываются от методики «ученико-час»? //Вести образования, 3 апреля 2019._— [Электронный ресурс]. URL: https:// vogazeta.ru/articles/2019/4/3/analitycs/6906-pochemu_regiony_otkazyvayutsya_ot_metodiki_ucheniko_chas

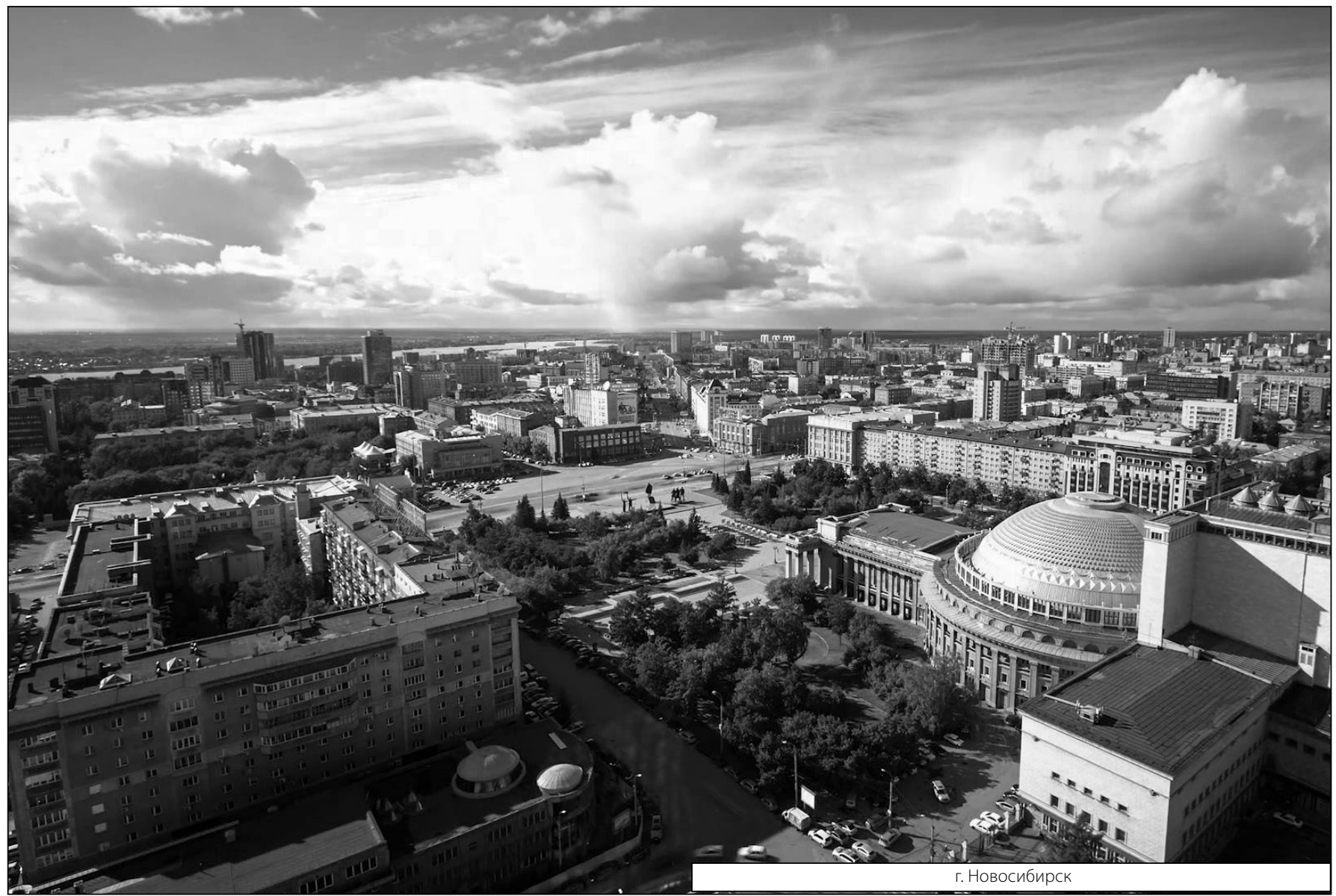

